\title{
Chronic kidney disease in low-middle income populations: a call to action for screening and prevention
}

\author{
Anna Paini $^{2} \cdot$ Massimo Salvetti $^{1,2} \cdot$ Silvio Caligaris $^{3} \cdot$ Francesco Castelli $^{1,4} \cdot$ Maria Lorenza Muiesan $^{1,2}{ }^{\infty}$
}

Received: 19 November 2018 / Accepted: 29 November 2018 / Published online: 6 December 2018

c) Società Italiana di Medicina Interna (SIMI) 2018

It has been estimated that about 5-10 million people die each year from kidney disease. The incidence and the prevalence of chronic kidney disease (CKD) are increasing worldwide. The true burden of kidney disease should be better assessed and prevented; in fact this worldwide health problem is probably underestimated, because of the relative lack of epidemiological data, the poor awareness of the problem, and the limited access to laboratory examinations for most of the general population in low-middle income countries [1-4]. A recent analysis of all the available studies published between 2008 and 2014, reporting the prevalence of CKD in Nigeria, finds a high prevalence of CKD in the country, ranging from 2.5 to $26 \%$, with a high variability according to the examined population, but probably also influenced by the equation used to estimate the glomerular filtration rate (GFR) [5].

It is well known that in low-middle income countries (where most of the migrants come from), the health profile of people is rapidly changing. The Global Burden of Disease Studies show a robust trend towards a longer life expectancy [1]: the progressive decrease in the rates of communicable, maternal, and child diseases is associated with an increased number of years of life lost, due to non-communicable conditions such as diabetes mellitus, cardiovascular diseases, neoplasm and others, including chronic kidney disease [2]. In 2016, it was reported that the disability-adjusted life-years (DALYs) associated with chronic kidney disease, along with those associated with cardiovascular disease, cancers, diabetes and neurological disorders had increased significantly

Maria Lorenza Muiesan

marialorenza.muiesan@unibs.it

1 Department of Clinical and Experimental Sciences, University of Brescia, Brescia, Italy

2 2a Medicina Spedali Civili, Brescia, Italy

3 SSVD Malattie Infettive ad Indirizzo Tropicale, Spedali Civili, Brescia, Italy

4 Department of Infectious and Tropical Diseases, Spedali Civili, Brescia, Italy between 1990 and 2015 [6]. Several areas in the developing world are experiencing the deleterious effects of noncommunicable diseases with an increase in morbidity and mortality from stroke, coronary artery disease and end-stage renal disease. Obesity, diabetes mellitus and hypertension are becoming a significant public health concern especially in urban residents $[3,7]$ where a higher prevalence of cardiovascular diseases [8], diabetes [9, 10] and kidney diseases $[4,11,12]$ in foreign-born populations in most migrants' destination countries have been described.

The influence of specific risks for acute and chronic kidney disease may occur across the socio-economic spectrum, with a considerable overlap of non-communicable conditions and infectious diseases $[13,14]$. Infectious diseases such as tuberculosis or schisostomiasis are frequently neglected, and treatment for acquired immunodeficiency implies the development of risk factors (hypertension, diabetes, metabolic syndrome) favoring cardiovascular events.

Many low-income countries have problems with undernutrition and overnutrition, which are both risk factors for kidney disease [15]. Malnutrition predisposes to diarrheal infections and pneumonia, resulting in renal complications and favoring acute kidney injury. In young females, malnutrition may predispose to bring underweight during pregnancy, as well as with low birth-weight offspring, low birth-weight represents a risk factor for future hypertension development and progressive loss of renal function. The opposite condition, i.e. obesity, increases the life time risk of CKD and cardiovascular disease. Maternal obesity during pregnancy is associated with adverse outcomes, increased risk of preeclampsia, and future development of cardiovascular and chronic kidney diseases.

The risks of kidney disease are influenced by a multifaceted and complex scenario of economic and health disparities, migration conditions and demographic transition. The HELIUS (HEalthy Life in an Urban setting) Study in Amsterdam was prospectively conducted with the aim of assessing the association between genetic factors, 
country-specific culture, migration history, ethnic identity, socio-economic and discriminatory factors with the incidence of diseases (cardiovascular, including diabetes, depressive disorders and drug abuse, infectious diseases) in four different ethnic groups: Suriname (both Afro-Caraibic and Southern Asia), Ghana, Turkey, Morocco and Dutch natives [16]. In the framework of the HELIUS study, Adjei et al. describe the prevalence of high to very high CKD risk among all ethnic minority groups (Turkish, Moroccans, South-Asian Surinamese, Ghanaians, and African Surinamese) compared with the Dutch host population [17]. All ethnic minority groups have higher odds of albuminuria, and high to very high CKD risk as compared to the Dutch even after adjustment for age and gender. Despite conventional risk factors (hypertension and diabetes) being more prevalent in all minority groups, they do not completely explain these ethnic differences suggesting that other factors play a role.

Adjustment for education and occupation reduces the odds between the Dutch and all ethnic minority groups, but does not fully explain ethnic differences in albuminuria and high to very high CKD risk [18]. This finding confirms previous evidence obtained among different populations in the United States and in Europe [19, 20]. The educational level may exert an influence on the development of CKD through unhealthy lifestyle and habits, poor access to a health care delivery system [19], and concomitant diseases. Suriname was a former Dutch colony, and accordingly both African and South-Asian Suriname had easier cultural access to preventive measures adopted by the Dutch host population, as compared to other ethnic migrant minorities. The occupational low level and the increased risk of CKD are usually explained by the possible effect of exposure and contact with nephrotoxic substances such as heavy metal (lead, mercury) organic solvents, glycol ethers, or grain dust. More frequently, a low occupational level mirrors poor food and lifestyle behavior.

The role of hypertension and blood pressure treatment may be determinant in the development of CKD [21]. A recent meta-analysis by Modesti et al. [22] shows a higher systolic and diastolic blood pressure in migrants from SubSaharan Africa to Europe than European residents, lasting for many years and refractory to preventive strategies. However, the opposite is true for migrants from Southern Asia, suggesting inter-ethnic differences. Also, Muslim migrants show lower blood pressure values, suggesting that religionbound alimentary habits also play an important role [21, 22].

Very recently, higher values of systolic and pulse pressures are observed in subjects living in a semi-urban than in a rural population in Ghana. Both systolic and pulse pressure are progressively increasing with age in men and women, despite the rise being more marked in women. The pulse pressure is significantly related to a decrease in creatinine clearance, more than all the other measures of blood pressure. The higher pulse pressure observed in the semi-urban population is associated with a parallel increase in body mass index, mainly in women; in the multivariate analysis only age and body mass index are independently associated with a decline in kidney function suggesting that pulse pressure might reflect an early vascular aging [23]. On the other hand, in a rural sample of subjects living in Tanzania, increased blood pressure and hyperglycemia are frequently recorded, but not associated with a relevant prevalence of CKD, mainly observed in younger subjects. The data suggest the need for a deeper insights in the causes of CKD [24].

In the study published in this issue of $I \& E M$ journal, Nannan Panday et al. [25] report the results of the HELISUR (the Healthy Life in Suriname) project aimed to assess cardiovascular risk factors as well as asymptomatic and symptomatic target organ damage including CKD in a random population sample of 1800 men and women aged 18-70 years. After a detailed interview at home, including the collection demographic, socio-economic, dietary, and health-related questions, the participants were invited to undergo a medical visit and laboratory examinations.

They describe a prevalence of CKD of 5\% in this group, of around 50\% South-Asian or African ethnicity. A very high prevalence of hypertension (72\%), overweight or obesity $(78 \%)$ and diabetes or prediabetes $(26 \%)$ was observed in the study participants. The authors have estimated that 6650 to 10,750 patients per million population may develop kidney failure in the future 10 years, leading to a dramatic medical, economic and social burden related to the disease, in the absence of specific policies for CKD management.

Unfortunately in the study, no data are available about the previous or current medical treatment of the study participants. It is also well demonstrated and suggested by guidelines $[26,27]$ that $\mathrm{BP}$ reduction preferentially obtained by the use of ACE- or ARB-based treatment is the most powerful tool to retard progression toward ESRD in CKD patients, and is very effective in reducing proteinuria [28]. Unfortunately access to medical treatment is still poor [29], and it is clear that poverty is associated with limited pharmacological control of chronic diseases, as well as because of lack of compliance [30].

Overall, the results of the study by Nannan Panday et al. [25] underscore the growing role of CKD in low-middle income countries morbidity and mortality. These results emphasize the importance of devoting more attention to CKD screening [31] and prevention, mainly focusing on diabetes and hypertension treatment to avoid the tremendous social and economic burden related to this disease. 


\section{Compliance with ethical standards}

Conflict of interest All authors declare no conflict of interest or potential influence or impart bias on the work.

Statement of human and animal rights This article does not contain any studies with human participants or animals performed by any of the authors.

Informed consent None.

\section{References}

1. Murray CJL, The GBD 2016 Mortality Collaborators (2017) Global, regional, and national under-5 mortality, adult mortality, age-specific mortality, and life expectancy, 1970-2016: a systematic analysis for the Global Burden of Disease Study 2016. Lancet 390:1084-1150

2. Murray CJL, The GBD 2016 Causes of Death Collaborators (2017) Global, regional, and national age-sex specific mortality for 264 causes of death, 1980-2016: a systematic analysis for the Global Burden of Disease Study 2016. Lancet 390:1151-1210

3. Rossier C, Soura AB, Duthé G, Findley S (2014) Non-communicable disease mortality and risk factors in formal and informal neighborhoods, ouagadougou, burkina faso: evidence from a health and demographic surveillance system. PLoS One 9(12):113780

4. Perico N, Remuzzi G (2016) Prevention programs for chronic kidney disease in low-income countries. Intern Emerg Med 11:385-389

5. Chukwuonye II, Ogah OS, Anyabolu EN, Ohagwu KA, Nwabuko OC, Onwuchekwa U, Chukwuonye ME, Obi EC, Oviasu E (2018) Prevalence of chronic kidney disease in Nigeria: systematic review of population-based studies. Int J Nephrol Renovasc Dis 22(11):165-172

6. Kassebaum NJ, Arora M, Barber RM, Bhutta ZA, Brown J, Carter A et al (2016) Global, regional, and national disabilityadjusted life-years (DALYs) for 315 diseases and injuries and healthy life expectancy (HALE), 1990-2015: a systematic analysis for the Global Burden of Disease Study 2015. Lancet 388(10053):1603-1658

7. Agyemang C, de-Graft Aikins A, Bhopal R (2012) Ethnicity and cardiovascular health research: pushing the boundaries by including comparison populations in the countries of origin. Ethn Health 17:579-596

8. Modesti PA, Bianchi S, Borghi C, Cameli M, Capasso G, Ceriello A et al (2014) Cardiovascular health in migrants: current status and issues for prevention. A collaborative multidisciplinary task force report. J Cardiovasc Med 15(9):683-692

9. Montesi L, Turchese Caletti M, Marchesini G (2016) Diabetes in migrants and ethnic minorities in a changing world. World $\mathrm{J}$ Diabetes 7(3):34-44

10. Animaw W, Seyoum Y (2017) Increasing prevalence of diabetes mellitus in a developing country and its related factors. PLoS One 12(11):e0187670

11. Stanifer JW, Muiru A, Jafar TH, Patel UD (2016) Chronic kidney disease in low- and middle-income countries. Nephrol Dial Transplant 31:868-874

12. Neuen BL, Chadban SJ, Demaio AR, Johnson DW, Perkovic V (2017) Chronic kidney disease and the global NCDs agenda. BMJ Glob Health. 2:e000380

13. Peer $N(2015)$ The converging burdens of infectious and noncommunicable diseases in rural-to-urban migrant Sub-Saharan
African populations: a focus on HIV/AIDS, tuberculosis and cardio-metabolic diseases. Travel Dis Travel Med Vac 1:6

14. Hodel NC, Hamad A, Praehauser C, Mwangoka G, Kasella IM, Reither K, Abdulla S, Hatz CFR, Mayr M (2018) The epidemiology of chronic kidney disease and the association with noncommunicable and communicable disorders in a population of sub-Saharan Africa. PLoS One 13(10):e0205326

15. Luyckx V, Tonelli M, Stanifer JW (2018) The global burden of kidney disease and the sustainable development goals. Bull World Health Organ 96:414C-422C

16. Stronks K, Snijder MB, Peters RJG, Prins M, Schene AH, Zwinderman AH (2013) Unravelling the impact of ethnicity on health in Europe: the HELIUS study. BMC Public Health 13:402

17. Agyemang C, Snijder MB, Adjei DN, van den Born BJ, Modesti PA, Peters RJ, Stronks K, Vogt L (2016) Ethnic disparities in CKD in the Netherlands: the healthy life in an urban setting (HELIUS) study. Am J Kidney Dis 67(3):391-399

18. Adjei DN, Stronks K, Adu D, Snijder MB, Modesti PA, Peters RJG, Vogt L, Agyemang C (2017) Relationship between educational and occupational levels, and Chronic Kidney Disease in a multi-ethnic sample-the HELIUS study. PLoS One 12(11):e0186460

19. Shoham DA, Vupputuri S, Kshirsagar AV (2005) Chronic kidney disease and life course socioeconomic status: a review. Adv Chronic Kidney Dis 12(1):56-63

20. Bello AK, Peters J, Rigby J, Rahman AA, El Nahas M (2008) Socioeconomic status and chronic kidney disease at presentation to a renal service in the United Kingdom. Clin J Am Soc Nephrol 3(5):1316-1323

21. Ibrahim MM, Damasceno A (2012) Hypertension in developing countries. Lancet 380:611-619

22. Modesti PA, Reboldi G, Cappuccio FP, Agyemang C, Remuzzi G, Rapi S et al (2016) Panethnic differences in blood pressure in Europe: a systematic review and meta-analysis. PLoS One 11(1): $\mathrm{e} 0147601$

23. Banerjee D, Plange-Rhule J, Chitalia N, Kumi K, Micah FB, Cappuccio FP, Eastwood JB (2018) Pulse pressure relationships with demographics and kidney function in Ashanti, Ghana. Int J Hypertens 4(2018):7864564

24. Udler MS, Nadkarni GN, Belbin G, Lotay V, Wyatt C, Gottesman O, Bottinger EP, Kenny EE, Peter I (2015) Effect of genetic African ancestry on eGFR and kidney disease. J Am Soc Nephrol 26(7):1682-1692

25. Nannan Panday R, Haan Y, Diemer F, Punwasi A, Rommy C, Heerenveen I, van Montfrans GA, Brewster LM (2018) Chronic kidney disease and kidney health care status: the healthy life in Suriname (HeliSur) study. Intern Emerg Med. https://doi. org/10.1007/s11739-018-1962-3

26. Williams B, Mancia G, Spiering W, Agabiti Rosei E, Azizi M, Burnier M, Clement D, Coca A, De Simone G, Dominiczak A, Kahan T, Mahfoud F, Redon J, Ruilope L, Zanchetti A, Kerins M, Kjeldsen S, Kreutz R, Laurent S, Lip GYH, McManus R, Narkiewicz K, Ruschitzka F, Schmieder R, Shlyakhto E, Tsioufis K, Aboyans V, Desormais I, List of Authors/Task Force Members (2018) 2018 Practice guidelines for the management of arterial hypertension of the European Society of Hypertension and the European Society of Cardiology: ESH/ESC Task Force for the Management of Arterial Hypertension. J Hypertens 36(12):2284-2309

27. Doshi SM, Friedman AN (2017) Diagnosis and management of type 2 diabetic kidney disease. Clin J Am Soc Nephrol 12(8):1366-1373. https://doi.org/10.2215/CJN.11111016 (Epub 2017 Mar 9)

28. Viazzi F, Leoncini G, Grassi G, Pontremoli R (2018) Antihypertensive treatment and renal protection: is there a J-curve relationship? J Clin Hypertens (Greenwich) 20(11):1560-1574 
29. Liyanage $\mathrm{T}$, Ninomiya $\mathrm{T}$, Jha $\mathrm{V}$ et al (2015) Worldwide access to treatment for end-stage kidney disease: a systematic review. Lancet 385:1975-1982

30. Cappuccio FP, Miller MA (2016) Cardiovascular disease and hypertension in sub-Saharan Africa: burden, risk and interventions. Intern Emerg Med 11:299-305
31. George C, Mogueo A, Okpechi I, Echouffo-Tcheugui JB, Kengne AP (2017) Chronic kidney disease in low-income to middleincome countries: the case for increased screening. BMJ Glob Health 2(2):e000256 